\title{
A SYSTEMATIC METHOD FOR RAPID RESOURCE ASSESSMENT
}

UF UNDEVELOPED REGIONS*

\author{
A. H. Voelker \\ Energy Division \\ Oak Ridge National Laboratory \\ Oak Ridge, Tennessee 37830
}

\section{ABSTRACT}

By acceptance of this article, the publisher or recipient acknowledges the U.S. Government's right to retain a nonexclusive, royalty-free license in and to any copyright covering the article.

A versatile method has been developed to rate the energy- and mineral-resource potentials of areas in which land management and resource development decisions must be reached with a minimum expenditure of money and time. The method (1) surveys published and personal information on resources in the region being assessed, (2) selects the most appropriate information, (3) synthesizes the information into map overlays and tract descriptions, (4) rates the potential of tracts for particular resources, (5) rates the overall importance of each tract for resource development, and (6) documents the ratings and their significance.

The method differs from traditional assessment procedures in three significant ways. First, when time constraints preclude gathering new data, the method operates on existing data and the personal knowledge of experts. Second, the design of the subjective rating process is based on principles of small-group interaction. Data synthesis, consensus building, and internal rating checks are facilitated by this design. Third, the

\footnotetext{
* Research sponsored by the Division of Biomedical and Environmental Research, U.S. Department of Energy, under contract W-7405-eng-26, with the Union Carbide Corporation.
} 


\section{DISCLAIMER}

This report was prepared as an account of work sponsored by an agency of the United States Government. Neither the United States Government nor any agency Thereof, nor any of their employees, makes any warranty, express or implied, or assumes any legal liability or responsibility for the accuracy, completeness, or usefulness of any information, apparatus, product, or process disclosed, or represents that its use would not infringe privately owned rights. Reference herein to any specific commercial product, process, or service by trade name, trademark, manufacturer, or otherwise does not necessarily constitute or imply its endorsement, recommendation, or favoring by the United States Government or any agency thereof. The views and opinions of authors expressed herein do not necessarily state or reflect those of the United States Government or any agency thereof. 


\section{DISCLAIMER}

Portions of this document may be illegible in electronic image products. Images are produced from the best available original document. 
method produces three unique ratings to aid the decision maker." Two of these ratings are coupled in a dual rating that delineates the geologic favorability of the area for each resource and the certainty of each resource's occurrence in the area. Both favorability and certainty are scaled from 1 through 4. Once dual ratings are assigned for a tract; the third rating, overall importance, is assigned to the tract by using predetermined criteria, individual resource ratings, and other pertinent background information gathered prior to the rating exercise. Basic criteria considered by the assessment team include (1) the favorability and certainty ratings, (2) the overall availability of each rated resource within this country, (3) the size of a given tract,. (4) economic factors, and (5) the number of resources in a tract.

The method has been applied to two separate but roughly similar geologic regions: Areas within these regions being considered for possible wilderness designation were rated for their resource potential, and the results were communicated to the appropriate land managers. A comparison of the ratings by this method with ratings produced by other groups demonstrates general agreement but shows this method to be more: sensitive than other methods to individual area anomalies. 


\section{INTRODUCTION}

Greater demand and higher prices for energy and mineral resources have focused attention on exploration and development of lands previously considered to have low resource potential. Because of past inatention, these lands are not well known, and resource developers do not generally have sufficient data to make well-informed resource decisions without new exploration. However, competing and of ten exclusionary land uses. such as wildlife refuges, national parks, or wilderness are forcing premature land-use decisions well in advance of the normal exploration/development cycle. Therefore, a need exists for rapid but valid procedures for. determining the geologic resource potential of areas being considered for exclusionary uses, the objective being to retain options for the exploration of those areas with high resource potential. Such procedures must be rapid and must use existing data whenever time and money do not allow the collection of field data. The method described here satisfies these requirements through both an improved rating concept and a carefuliy designed procedure.

Decision makers attempting to interpret and apply the results of past resource assessments to multiple land-use questions have experienced two problems. First, traditional assessment studies normally take from one to three years, depending on the size of the area being studied. Mounting pressure for exclusionary landuses makes such time periods inadequate to identify and protect areas of high resource potential. Second, the manner in which results of assessments are reported is usually not meaningful to the land manager or politician untrained in geology or mineral resources. Data and interpretations are reported in a 
factual manner; resources are not rated formally, and no value judgment on the overall importance of the tract is attempted.

Such value-free reporting is done in part to preserve the "scientific" objectivity of the study but also in part to avoid forcing the participating agencies into consensus on value issues. The decision of tract worth is left to the land manager or the politician.: Unfortunately, these decision makers have little skill in interpreting the geologists' tables or their guarded statements about possible new deposits. Our method attempts to bridge this communication gap with precisely defined ratings and documentation that allow a given rating to be traced and checked through independent means.

\section{THE METHOD}

The method depends on the efficiency of a tightly knit team of experts who move systematicaliy through a series of decision steps. A core team of three individuals manages the process and maintains continuity throughout the several months required to conduct a regional assessment.

Primary tasks of the core team are to gather and synthesize data, to conduct rating sessions, and to document results. The data synthesis and rating activities culminate in two intensive work sessions that involve invited experts to bring greater personal knowledge and understanding into the process and to validate the data and conclusions of the core team. The method depends on the collective judgment and personal knowledge of the team plus invited experts (1) to adopt appropriate resource-occurrence models, (2) to interpret and supplement available data, (3) to extrapolate available data to tracts being evaluated, and (4) to rate the resource potential of the tracts. The output of this effort is carefully documented 
nn (1) map overlays that show significant geologic features and favorable areas for each resource and (2) assessment forms for each tract that list resource ratings and supporting information.

A review of the few approaches that have attempted to rate subarea resource potential revealed that such systems usually create a single rating by combining an estimate of the likelihood of resource accumulation with data on mineral occurrences. Usually, no attempt is made to show the reasoning followed in creating a rating. Such ratings are of ten inconsistent and/or unduly influenced by occurrence data (Voelker 1979, Sect. 3.2). Furthermore, although a single rating for each subarea is needed to identify that group of subareas having high resource potential, " it is not adequate to make well-informed decisions between subareas in that group.

The method overcomes these deficiencies by means of three unique ratings. Data is interpreted and synthesized by the core team and invited experts to create a dual rating of each subarea for each resource. 'These ratings are then considered with other information to create an overall importance rating for each subarea.* The sequence of steps followed in generating the importance rating forces the core team through a logical thought process and allows the decision maker or technical expert to trace the process followed.

\footnotetext{
${ }^{*}$ The overall importance rating is equivalent to the single rating discussed above but is superior for reasons to be described.
} 
The dual rating characterizes both the geologic favorability of an area for each resource and the certainty that the resource occurs in. the area. Favorability is defined as the potential of a particular geologic environment to contain exploitable quantities of mineral resources. The favorability of any region for a particular resource is based on commonly accepted occurrence models. These models are usually only mental constructs that try to explain the geological processes that have combined to produce a mineral deposit. It is possible to apply a model developed. for one region to another region with similar geology, although the new region may not be developed or even explored. The favorability rating relies on the ability of resource specialists to draw such inferences through resource-occurrence models. In this way, it is possible to rate the favorability of undeveloped regions for which the geology is known but for which little exploration has been accomplished. The rating is scaled between 1 and 4 , and explicit definitions have been developed for each of the four levels.

Certainty refers to the presence or absence of a resource in a tract. The degree of certainty is fundamentally a statement of region-specific or site-specific occurrence and usually requires the extrapolation of these data to the tract from currently producing mining districts, old mining districts, oil and gas fields, or other direct evidence of resource occurrence. Thus, certainty depends on past or current production, specific sampling, and detailed mineral investigations. ${ }^{*}$ Certainty is scaled from 1 to 4 , and each of the four levels has an explicit definition.

Favorability and certainty are not completely independent because a high certainty (good data on resource existence or nonexistence nearby) will modify local favorability. Thus, these ratings are assigned simultaneously. 
The third rating, overall importance, is assigned by the team to each subarea to give the decision maker an expert opinion on the value of subareas in meeting future resource needs. The decision maker can use this rating in comparing other possible land uses such as recreation, wilderness, or timber harvesting to mineral development or for eliminating subareas from further consideration for mineral development. Choices. between particular subareas would involve the favorability/certainty ratings. Overall importance is rated between 1 and 4 .

In rating overall importance of a subarea, the team synthesizes the dual ratings of individual resources, personal knowledge, and supporting data. They rate each subarea in turn by using a predetermined set of criteria. Typically, criteria place a higher value on subareas with the potential for strategic minerals, subareas with favorable accessibility, large subareas, subareas with more than one mineral, and subareas with other uses compatible with mineral development.

In considering the trade-offs between two subareas, the decision maker can refer to individual resource dual ratings and background data on an assessment form developed by the team for each area evaluated. Figure 1 shows such a form completed in a recent application.

The form consists of three sections: descriptive data, ratings, and supporting information: Note that, when available, other ratings are recorded as extra input to the rating process: The supporting information section is relatively unstructured; and.the team is free to record any reference or supporting statements that would facilitate trade-off decisions and allow the decision maker or independent expert to trace the basis of the team rating. 
TRACT NO: 04170

NATIONAL FOREST: Car.ibou
TRACT NAME: Red Mounta in

ECOREG : 3112

WAR: 19

ACREAGE (GROSS): 13,800 ACREAGE (NET): $13,800100 \mathrm{~N} / \mathrm{G}: 100$ LATIIUDE: $42^{\circ} 27^{\prime}$ LONGITUDE: $111^{\circ} 07^{\prime}$

\begin{tabular}{|c|c|c|c|c|}
\hline $\begin{array}{l}\text { INDIVIDUAL TRACT } \\
\text { RESOURCE RATINGS }\end{array}$ & ORNL & USFS & DOE & USGS \\
\hline OIL AND GAS & $4 / 3$ & 4 & 4 & \\
\hline URANIUM & $3 / 1$. & 1 & 1 & \\
\hline COAL & $1 / 3$ & 1 & 1 & . \\
\hline GEOTHERMAL & $3 / 2$ & 1 & & \\
\hline CRIITICAL MINERALS & $3 / 2$ & 1 & & . \\
\hline $\begin{array}{l}\text { UVERALL RATING } \\
\text { (WEIGHTED) }\end{array}$ & $3^{+}$ & & 4 & \\
\hline
\end{tabular}

Stratigraphic and structural traps compounded by thrusting; similar to Canadian Rockies Foothills Belt.

NAMES OF CRITICAL MINERALS PRESENT: CU

COMMENTARY AND SUMMARY: Several major and several lesser oil and/or gas fields are located in the southern part of the Absaroka Belt in Wyoning and Utah. Most production is from Jurassic-Triassic reservoirs, but more recent deeper discoveries are in Upper Paleozoic rocks (Phosphoria) and even more recently in Lower Paleozoic rocks. The Rocky Mountain 0il and Gas Association estimates that Rare II tracts in the Absaroka belt contain nearly 3.3 billion barrels of oil and over 12.5 trillion cubic feet of gas.. The major part of the Southeast Idaho phosphate resource is in this thrust belt, with much of it in the Rare Ii tracts. Not only are the phosphate rock resources important for the phosphorus, but there is a significant near-future potential for vanadium, uranium by-product production. The Mt. Pisgah gold district in Bonneville County may have significant potential for Carlin-type gold deposits (Rare II tracts. 04160, 04161, and 04162). DOE, moderate corridor conflict (R-45).

GEOLOGY: Absaroka thrust belt (includes terrain westward to surface trace of the Paris-Bannock thrust complex). Includes (as secondary structures) the Crawford, Meade. Medicine Lodge, Sheep Mountain, Skyline, and many smaller thrust faults. Rocks exposed at the surface include sedimentary rocks from Cambrian to Tertiary in age along with some Tertiary and Quaternary volcanics. Several small igneous intrusions of Tertiary Age have been mapped in the. Idaho part of the Absaroka Belt, chiefly in the vicinity of the Mt: Pisgah gold district.

REFERENCE/CITATION: USFS, 1978, RARE II OES, ID. UT, and WY Suppls.; DOE, 1978, Energy Res. Assessments. of RARE II Lands; DOE, 1978, Energy Res. Assessments, of Ten Alternatives-RARE II Lands; Powers, 1977, WGA Gdbk 29; Blackstone, 1978, Tectonic map of the Overthrust Be1.t: WGS; RMOGA, 1978, Es timates of Undiscovered Recoverable Hydrocarbon Resources (RARE-II); White and Williams, 1975, USGS Circ. 726 NOAA, 1977, Geothermal Energy Resources of the Western U.S.; USGS, 1945, Min. Res. Mo. Valley Region, : Pts. 1,2,3; FRDA, 1976. NURE-Prelim.Rpt.; Armstrong and Oriel, 1965, AAPG Bull.., v. 43; British Sulfur Corp., Ltd., 1964, A World Survey of Phosphate Deposits: Woodalils Ltd. (Printers), London; Gulbrandsen, 1966, Geochim. Cosmochim. Acta, v. 3, p. 769-778; Brobst and Pratt, 1973, USGS Prof. Paper 820; Worl and 0thers, 1974, USGS MR-60; Kinkel and Peterson, 1962, USGS MR-13; RMAG, 197.2, Geologic Atlas of the Rocky Mountain Region: Denver, C0; Bond and Others, 1978, Geologic Map of Idaho: 1BMG;. Ros5, C.P., 1941, IBMG Pamph. 57,.pt. 111; Mansfield, 1927, USGS Prof. Paper 152; Leonard and 0thers, 1978, USGS. OFR 78-360; USGS, 1964, Mineral and Water Resources of Idaho: 88 th U.S. Congress; Vine, 1959, USGS Bul1. 1055-1.

Fig. 1. Assessment form for a proposed wilderness tract in the Idaho-Wyoming-Utah thrust belt. 
Because no formal analytical procedures or models are used in the method, the role of the computer is somewhat limited. However, by storing ratings in the computer, it is possible to check the accuracy and consistency of ratings by means of computer plots. The plots used are produced with standard display algorithms, are inexpensive to run, and do not require that the boundaries of tracts be digitized.

Figure 2 is a hand-drawn overlay showing proposed wilderness tracts that were assessed by the method in the Idaho-Wyoming-Utah thrust belt. Important geologic features are included. Figure 3 is a computerdrawn plot of critical mineral ratings in which circles are centered on the centroids of individual tracts. The size of each circle is proportional to the tract acreage. The left half of each circle displays the degree of favorability, and the right half displays the degree of certainty. Circles that are totally black have both high favorability and high certainty. The phosphate potential of the large tracts in the northeast give these tracts higher ratings. The small tracts in the southwest reflect the gold potential existing in this vicinity. An inspection of an earlier version of this plot convinced the assessment team that it had failed to rate this gold district high enough.

Figure 4 shows the overali importance rating of the thrust belt tracts. The amount of black in each circle indicates the relative importance of each tract. Again, the large northeastern tracts appear to be highly important and the gold district moderately important. By computerizing inventory information for each tract, it was possible to run a simple check on the internal consistency of the overall 
ORNL-DWG 78-16330

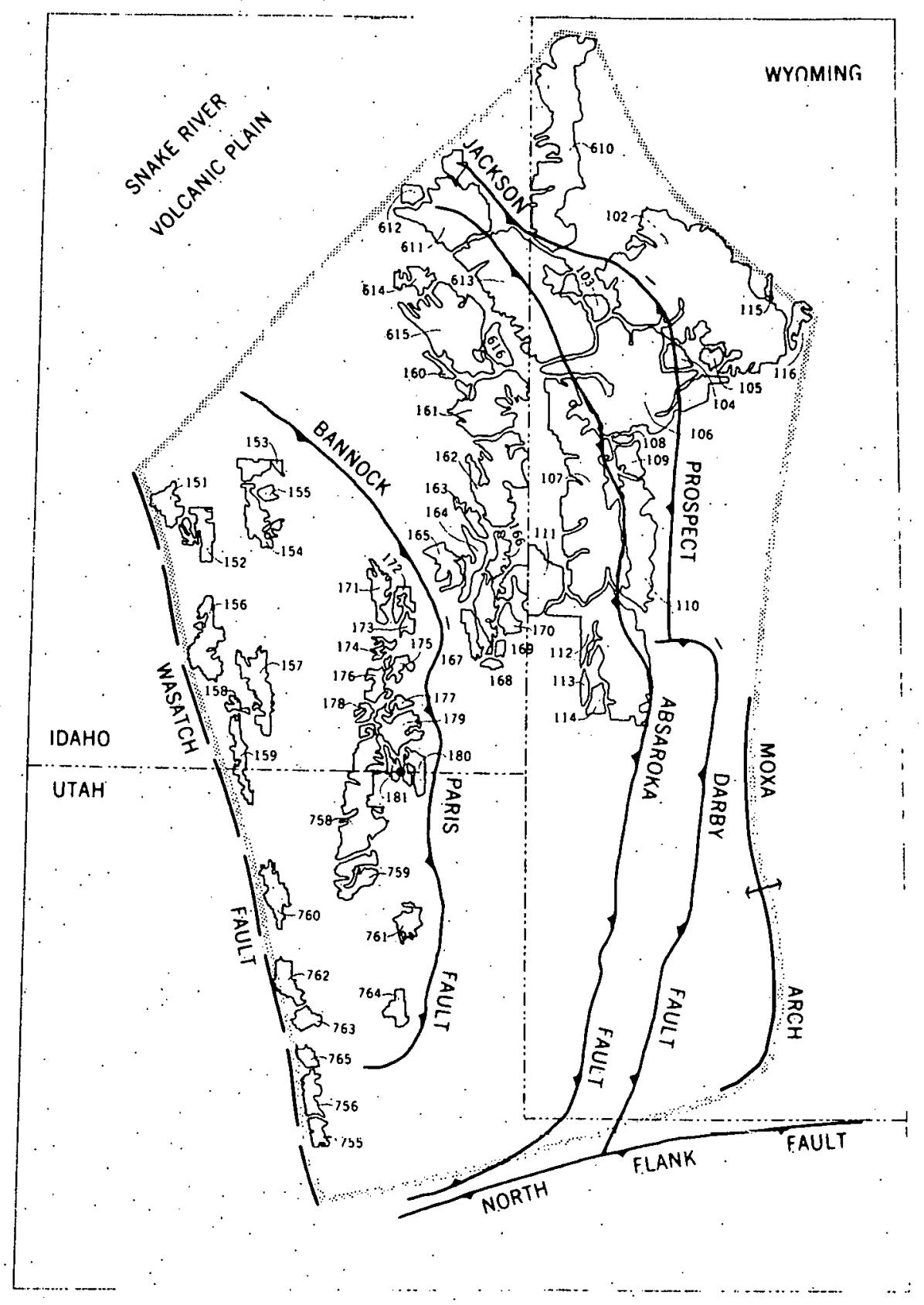

Fig. 2: Proposed wilderness tracts in the Idaho-Wyoming-Utah thrust belt. 


\section{ORNL-DWG 78-20226}

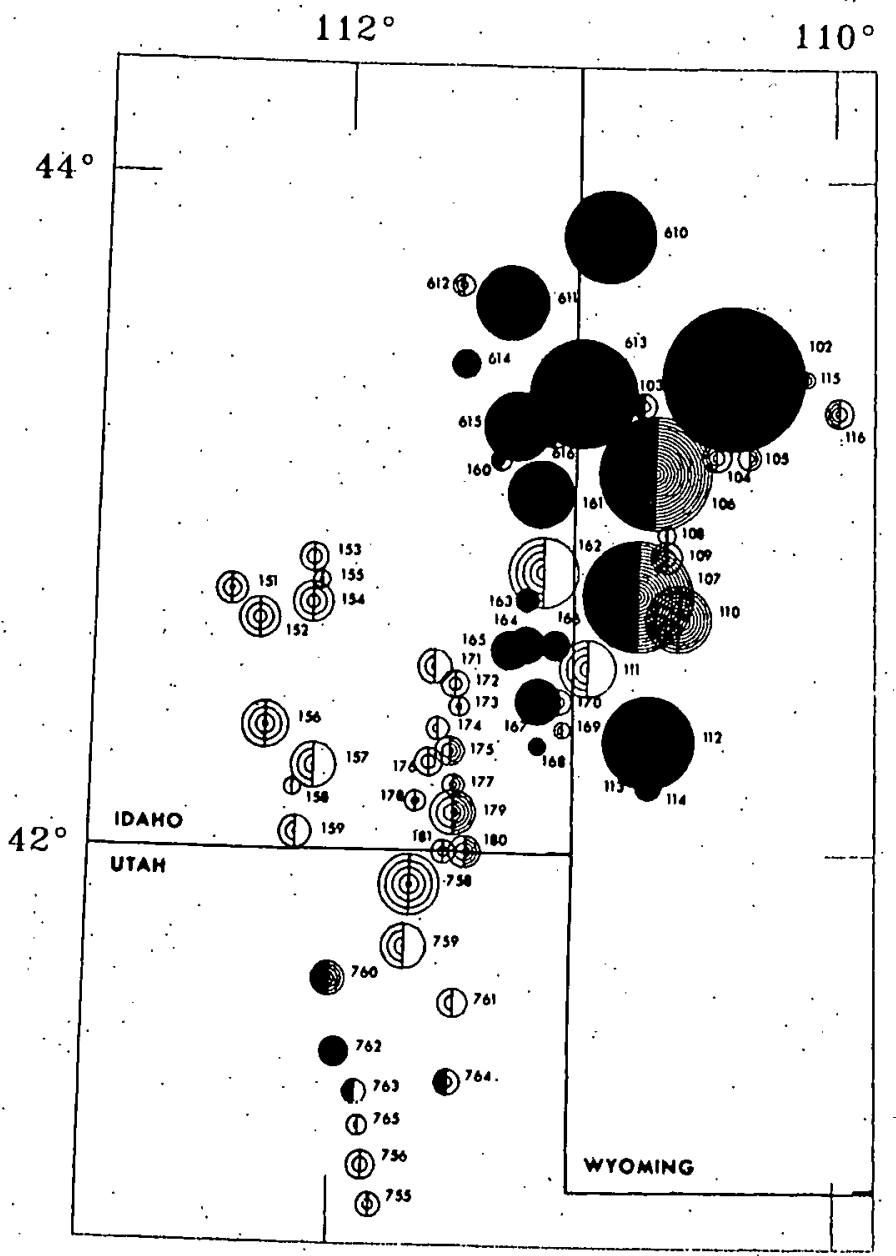

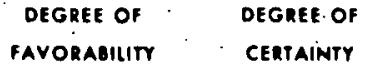

10 low $D$

$=$ (d)

,

1) HIGH

SIZE OF CIRCLE IS PROPORTIONAL to tract acreage

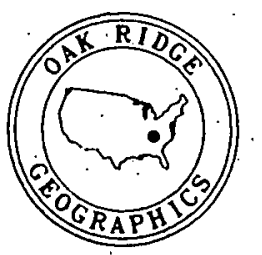

Fig. 3. Rating of critical minerals in the Idaho-Wyoming-Utah thrust belt. 


\section{ORNL-DWG 78-16336}

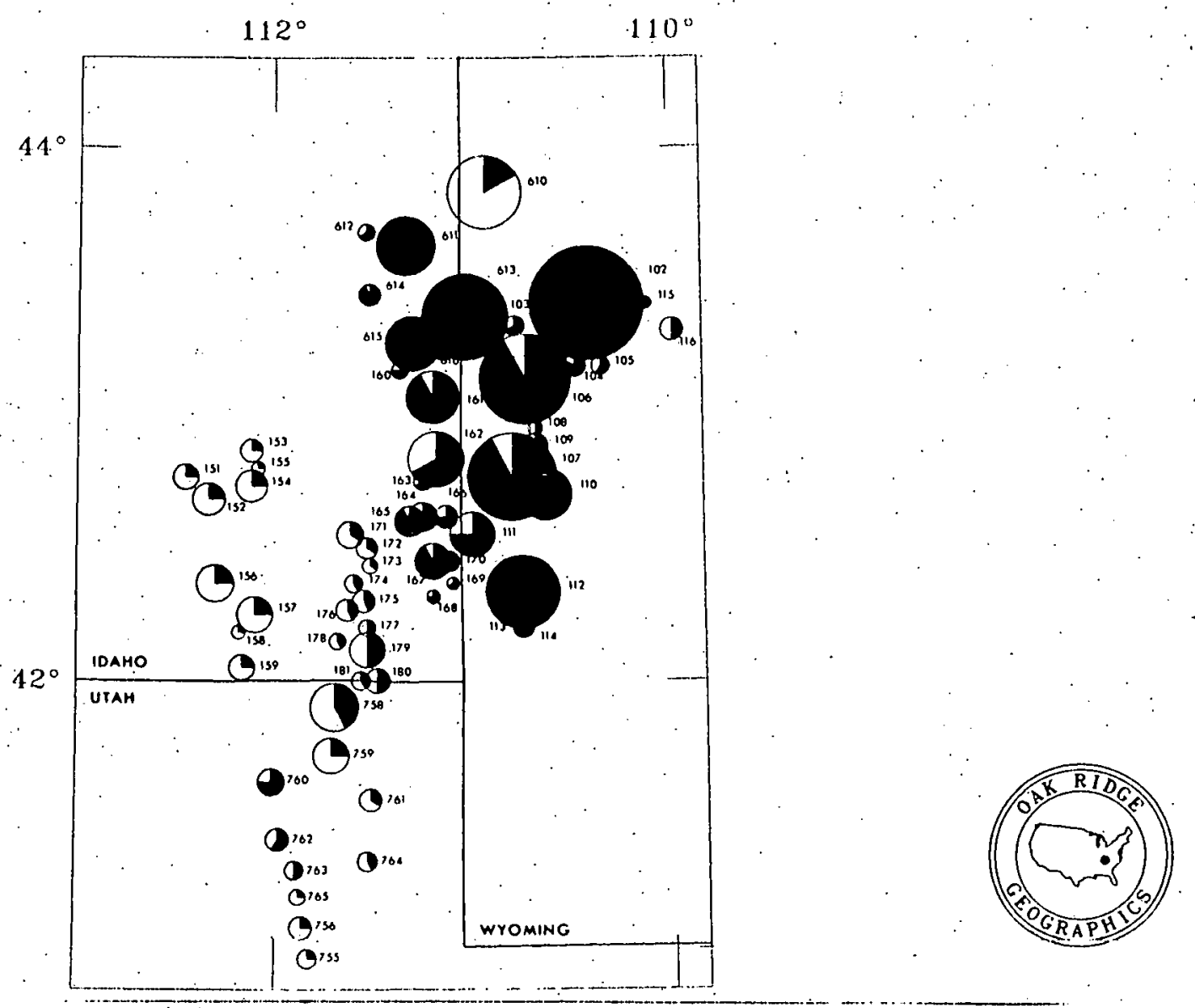

Fig. 4. Overall importance rating of proposed wilderness tracts in the Idaho-Wyoming-Utah thrust belt. Amount of black in circle is indicative of tract importance. 
importance ratings by using multiple linear regression. The overall rating (dependent variable) was regressed against tract acreage, favorability rating, and certainty rating for all resources (multiple independent variables). An $R^{2}$ of 0.88 was obtained by this check, which shows a consistent rating approach.

To determine if the method would produce consistent interregional ratings, proposed wilderness tracts were rated in a second region that has gross structural similarities. A statistical check of oil and gas ratings showed that the distribution of rating values correlated closely with the proportion of each region that has similar local geologic environments: Finally, method results were compared with ratings produced for the Idaho-Wyoming-Utah thrust belt by several governmental agencies. This check showed general agreement but also revealed that the method allowed better discrimination between tracts and resulted in a wider spread of overall importance ratings. In the next year, a group of tracts that have undergone lengthy traditional resource assessments including geochemical and geophysical testing will be assessed. The results will be compared with the conclusions reached by the traditional studies.

\section{CONCLUSION}

The state of the art in total resource assessment of geologic subprovinces is still poorly developed as a computer-based analytical procedure. In one approach, statistical models to estimate mineral tonnage and grade are being applied to large areas in Alaska by the U.S. Geological Survey (Singer 1978). However, this method is not applicable to relatively small areas because quantitative estimates become unreliable on this scale. Statistical models derived from past work in computerized pattern 
recognition are only beginning to be used for the prediction of resource occurrence (Botbol 1978). These models remain unproved and may not work well without input from field sampling. Thus, current resource assessment relies on the judgment and interpretive skills of resource experts. Much of the input and most of the decisions are subjective.

The method described here does not attempt to make resource assessment an objective process but, rather, attempts to structure the process into a logical step-by-step procedure that has feedback and interaction to test and correct fallacious subjective input. To accomplish such application of the "systems" approach, it is necessary to integrate social science principles of small group interaction with the improved assessment techniques of the earth sciences.

The method developed does have inherent limitations. Rapid assessment implies a dependence on limited existing data, particularly in undeveloped regions. Because the quality of the assessment is no better than the data available, the method output must be treated only as an initial judgment that is sufficient for beginning a planned exploration program or as an expedient for use in multiobjective land-use decisions whenever time or money preclude new data gathering.

However, the method retains its strength as a procedural guide and. communication device when supplied with better data. It is therefore possible to extend the assessment to incorporate field data gathering. Thus, it is possible to combine traditional assessment approaches with our design concepis to produce improved resource assessments. 


\section{REFERENCES}

1. Voelker, A. H; H. Wedow, E. Oakes, and P. K. Scheffler (1979) A. Systematic Method for Resource Rating with Two Applications to Potential Wilderness Areas: ORNL/TM-6729. Oak Ridge, Tennessee: Oak Ridge National Laboratory.

2. Singer, D. A., W. D. Menzie, and J. H. DeYoung, Jr. (1978) Regional Mineral Resource Asssessment in Alaska, A Case History. Presented to International Conference on Computer Mapping for Resource Analysis, Mexico City, May 8-10, 1978.

3. Botbol, J. M., R. Sinding-Larsen, R. B. McCammon, and G. B. Gott (1978) A Regionalized Multivariate Approach to Target Selection in Geochemical Exploration. Economic Geology 73: 534-46. 